\title{
Promises of the Modern Scientific Search for Human Nature's Multifaceted Soul
}

\author{
Mahmoud Dhaouadi
}

Since time immemorial, human beings have sought to understand the essence of human nature. One well-known explanation-human nature is dualistic, body and soul, and composed of organic and spiritual dimensions-has not ended the debate over subissues that proceed from the main concept of human nature. Our concem here is how the spirit and the body influence each other. As modern knowledge and science are far from having the last word in this domain, the perplexity of human nature continues to engage the attention of philosophers, psychologists, sociologists, and scientists. In real terms, nothing has changed in our dualistic human nature except its labeled names.

In general, modem psychologists have come to see the dualism of human nature in its innate/learned dimensions. Some modern philosophers have stuck by the asserted dualism of human nature, making only slight modifications concerning its spirit/body duality. For them, human nature consists of a body/mind dualism.' Modern scientists have also tried to solve the riddle of human nature's puzzling dualism. Behavioral psychologists have sought to eliminate entirely, or at least as much as possible, the innate state (the inner, spiritual dimension) of our dualistic human nature, with the result that they view the latter as no more than a mere reflection of the external environment(s). In a similar manner, the French sociologist Emile Durkheim has oriented his own sociology toward the concept of les faits sociaux, which he believed to be the only forces that one needed to consider when explaining human behavior. His resulting perspective bears a strong resemblance to behaviorism, for both desire to eliminate the innate, the psychological, and the spiritual side of human nature.

Contrary to Durkheim's rigid social determinism and behaviorism's narrow $S-R$, sociologists have emphasized the importance of human nature's innate biogenetic ${ }^{2}$ factors and how they shape and determine human behavior. For them, the social behavior of human and nonhuman living beings can be explained by biogenetic determinants. For example, the practice of not marrying one's very close relatives can be seen as a result 
of biogenetic factors: a) the resulting offspring would be subject to increased risk vis-à-vis physiological handicaps and inherited diseases passed from one generation to the other; and b) wide social acceptance of such marriages, sociologists would argue, would represent a long-term threat to the human race itself. It is because of this impending danger that most human societies have prohibited marriage between members of the same family and between close relatives. For sociobiologists, the social mores and cultural norms and values prohibiting such marriages are the result of biogenetic factors and not vice versa.

\section{Human Nature and the Modern Discoveries of the Brain/Mind}

Past and present scholars and scientists have reached consensus on the view that what distinguishes humans from nonhumans is the human capacity for advanced thought. It is on this basis that philosophers have called the human being a "thinking animal." Thus, a better understanding of human nature requires a deeper comprehension of the human brain $/ \mathrm{mind}^{3}$

Relevant modern studies have drawn two conclusions. First, the human being's death is no longer seen as dependent on the cessation of his/her heart's activity, for modern medicine has ruled that one dies when his/her brain stops functioning. Thus, it is the human brain that is at the center of a human being's life. This provides us with a partial explanation of why the human brain is held to be sacred. Although modern medicine has made great progress in the transplanting of various organs (e.g., the kidney, the liver, and the heart) from one individual to another, transplanting part(s) of the nervous system from one individual to another remains very controversial even within fully modernized countries. This may reflect the widely held belief that the brain is the temple of the human soul/spirit. Consequently, the transplanting of any part(s) of the nervous system may be seen as violating the spiritual sacredness of the brain. This tends to confirm the idea that the intimate relation between the soul and spiritualism is a strong one indeed. Traditional beliefs as well as modern scientific discoveries appear to concur on that relationship. ${ }^{4}$

Second, modern specialized scientific research has shown that the nervous system that forms the structure of the human brain is remarkably distinct from their nonhuman counterparts. The human brain has been described as "the most complex structure in the known universe"s and as "une machine hyper complexe," in the words of French philosopher/sociologist Edgar Morin. We now know that the human brain is made up of a left and a right hemisphere, both of which, despite all of their differences, complement the other. This complementarity, itself complex, is manifested in the plausibility of cooperation and conflict at the same time. Von Forster has referred to the human brain as a democratic organ, by which he means that it is not an authoritarian order-giving center but rather a confederation of many regions that enjoy a fair degree of autonomy. 
The human brain's complex structure must have a strong impact on the phenomenon of the cultural symbols that distinguish humans from other living beings and artificial intelligence (AI) machines. ${ }^{6}$ Spoken/written language, thought, religious beliefs, systems of knowledge/science, and cultural norms and values are exclusive characteristics of human individuals and societies. ${ }^{7}$ In other words, the phenomenon of culture in its anthropological and sociological meanings would not emerge and materialize in the absence of the human brain's distinct and complex organic structures.

Regardless of the definition of culture provided by social science references, books, or journals, we find a general consensus among them: culture represents the nonmaterialist (the symbolic, the spiritual) side of the human entity. Language, for instance, is the most important of all human cultural symbols and is the one cultural feature that distinguishes humans from nonhumans. The human mind is hardly capable of engaging itself in simple or complex thinking without the use of language. With language, human beings have the possibility of recreating the past and projecting themselves into the future. Thus, their behavior can be affected by the nonpresent past as well as the imaginary future. This linguistic resource empowers them to defy the time limitations of their physical body and predisposes them to hope for some sort of longevity or even eternity. Without language, it is hardly conceivable that ideas, parables, or wise statements could experience longevity or eternity. If the terms soul and spirit are usually associated with imperishable existence and thus with eternity, then language becomes the most legitimate means of impregnating human acts with metaphysical and spiritual touches.

Human beings address, pray to, and implore their gods verbally. This is another indication of the intimate relation between language as a cultural symbol and the emergence of religious symbols on the other. As such, language constitutes a cultural-symbolic means by which humans can flirt with the transcendental universe and ultimately reach out for it.

With the advancement of modern scientific research in those areas related to the human brain's organic structure and the functions of its parts, the specialists have become more interested in understanding the human brain as an entity of memorizing, rationalizing, and thinking, activitites that are not found among nonhuman species and the programs of AI machines. ${ }^{8}$ Ongoing discoveries in the field of artificial intelligence have led some researchers to be more optimistic concerning the understanding of the nature of the human mind. Cognitive psychology seeks to address the human mind $^{9}$ and to describe human thought structures and processes that could be charted within the brain as responses to external/internal stimuli. It is in this sense that the theories of cognitive psychology differ from biological and behavioral theories, for the former focus on the human brain's bioorganic structures while the latter do not pay great attention to the brain's internal processes and interactions, regardless of their biological or mental nature. 
In spite of this, the field of cognitive psychology has its own promises. With the cooperation of such disciplines as anthropology, psychology, linguistics, computer science, and philosophy, there is a greater hope of learning more about the secrets of the human mind. So far, this young field has discovered unconscious structures and processes in the human mind. ${ }^{10}$ Fodor, a well-known scientist in brain/mind research, has demonstrated that the human mind possesses many innate cognitive parts that specialize in controlling such activities as language and visual perception, which are both connected with the nervous system but function away from conscious perception and the intended control process. Such discoveries show that the study of the human mind is a top priority endeavor that could help us acquire a better understanding of human nature itself. Is it not the mind that distinguishes us the most from all other living species?

\section{The Human Being's Multiple Souls}

It can be said, therefore, that the human brain is the center of the human being's multiple souls (it should be noted that these souls are not of the same nature). Based on what has already been said, two souls can be identified in the human brain. The first soul can be called the "life making and sustaining soul," is found in all living creatures, and causes the death of the entire organism when its nervous system ceases to function. Revealing the secrets of this soul's nature constitute a considerable challenge, particularly to medical and biological sciences. As we read in Qur'an 17:85, "They ask you (O Muhammad) about the soul. Say, 'The soul's secrets are in God's hands' and you (human beings) were given only a little of the divine knowledge/science," appears to refer to this kind of soul.

The second type of soul is the set of cultural symbols: language, religion, thought, knowledge/science, and cultural norms and values. These cultural symbols are at the origin of the spiritual experience, consciousness, and feelings that so distinguish the human mind from its nonhuman counterparts." If humanity is to manage both the Earth and the space beyond it successfully, then clearly this type of soul is of critical importance. As has been shown above, the first type of soul is also found among nonhuman organisms. The second type, however, which consists of language use, the ability to think, adhering to religious beliefs, the practice of science/knowledge, are exclusively human characteristics. Humanity's superiority over all other living creature derives, without doubt, from its brain/mind, without which the emergence of the second soul would not be possible. ${ }^{12}$ The Qur'an appears to have used the word soul to refer to the knowing mind, whose intellectual/cultural characteristics have already been stressed. The Qur'anic verses 33:72-73 state: “And (remember) when thy Lord said unto the angels: Lo! I am about to create a mortal out of a potter's clay of black mud altered. So, when I have made him and breathed of My spirit (the use of cultural symbols, freedom to act, to choose), do ye fall down, prostrating yourselves unto him," could refer only to the second soul. The angels' 
prostration to Adam had become a required and suitable behavior only after God had breathed into him the cultural-symbolic mind.

According to the Qur'an, it is the divinely inspired human mind that renders humanity the only fit living creature to be accorded the responsibility (khiläfah) of governing this world. Humanity's civilizational accomplishments throughout its long history are obviously the outcome of the multitalented culturo-symbolic mind. Those who try to predict the future of modern civilization see no better alternative to the human mind as the agent most qualified to orient its present and future direction. Given the decisive role of the culturo-symbolic mind in determining both individual and socieal behsvior, discussions of human nature must give priority to the extreme importance of the human cognitive capacity.

Therefore, a reclassification of human nature's dualism is in order. In the traditional soul/body version of human nature, the term second soul (the culturo-symbolic mind) must take priority over the body component of human nature's dualism. Despite this modification, human nature's traditional body/soul formula remains credible from a scientific point of view. The latter has not only confirmed the presence of soul/spiritualism within the frontiers of human nature, but has enriched its meanings and deepened and amplified its levels, as these reflections have attempted to show.

\section{Endnotes}

1. J. Schaffer, Philosophy of Mind (Englewood Cliffs, NJ: Prentice Hall, 1968) and Sir J. Eccles, Mind and Brain: The Many Faceted Problems (New York: Paragon House Publishers, 1985).

2 . In recent years, many studies have demonstrated the genetic impact on the determination of human behavior. The personalities of identical twins raised in different social milieux have been of special interest for the study of the influence of genes on the similarity of behavior.

3. There are various modern scientific definitions of both the brain and the mind. The latter is seen as an emergent property of the brain's electrical and metabolic activity or as consciousness and a sense of self-awareness. The brain is considered as the organ of the mind. See the special issue of Scientific American on "Mind and Brain" (September 1992). tember 1962 .

4. "Cranial Pursuits Programs," Canadian Broadcasting Cooperation (CBC), 6 Sep-

5. Scientific American, 48.

6. Ibid. See articles on language, memory, and learning.

7. This is a widely used modern social science definition of these cultural symbols.

8. Scientific American.

9. H. Gardner, The Mind's New Science: A History of the Cognitive Revolution (New York: Basic Books, 1985).

10. Scientific American. See the article on the problem of consciousness, 153-59.

11. Ibid., 153-55.

12. Ibid. See articles on language, memory, and learning. 